\title{
Emergency Cricothyroidotomy in Difficult Airway Simulation - A National Observational Study of Air Ambulance Crew Performance
}

Åke Erling L. Andresen ( $\sim$ ake.erling.andresen@norskluftambulanse.no )

University of Oslo, Faculty of Medicine, Oslo

Jo Kramer-Johansen

Norwegian Advisory Unit on Prehospital Emergency Medicine (NAKOS), Oslo University Hospital, Oslo

Thomas Kristiansen

Department of Anaesthesiology, Division of Emergencies and Critical Care, Oslo University Hospital, Oslo

\section{Research Article}

Keywords: Emergency Medicine, Airway Management, Prehospital, Simulation, Quality Improvement

Posted Date: February 21st, 2022

DOI: https://doi.org/10.21203/rs.3.rs-1299190/v1

License: (c) (i) This work is licensed under a Creative Commons Attribution 4.0 International License. Read Full License

Version of Record: A version of this preprint was published at BMC Emergency Medicine on April 9th, 2022. See the published version at https://doi.org/10.1186/s12873-022-00624-6. 


\section{Abstract \\ Background}

Advanced prehospital airway management include complex procedures carried out in challenging environments, necessitating a high level of technical and non-technical skills. We aimed to describe Norwegian Air Ambulance-crews' performance in a difficult airway scenario simulation, ending with a "cannot intubate, cannot oxygenate"-situation.

\section{Methods}

The study describes Air Ambulance crews' management of a simulated difficult airway scenario. We used video-observation to assess time expenditure according to pre-defined time intervals and technical and non-technical performance was evaluated according to a structured evaluation-form.

\section{Results}

Thirty-six crews successfully completed the emergency cricothyroidotomy with mean procedural time 118 (SD: \pm 70 ) seconds. There was variation among the crews in terms of completed procedural steps, including preparation of equipment, patient- monitoring and management. The participants demonstrated uniform and appropriate situational awareness, and effective communication and resource utilization within the crews was evident.

\section{Conclusions}

We found that Norwegian Air Ambulance crews managed a prehospital "cannot intubate, cannot oxygenate"-situation with an emergency cricothyroidotomy under stressful conditions with effective communication and resource utilization, and within a reasonable timeframe. Some discrepancies between standard operating procedures and performance are observed. Further studies to assess the impact of check lists on procedural aspects of airway management in the prehospital environment are warranted.

\section{Background}

Airway management has the highest priority in emergency medicine, and basic airway management by opening and clearing airways is a core skill for all personnel in Emergency Medical Services (EMS). Successful prehospital airway management is associated with training and competence [1]. EMS frequently deliver tiered care, reserving interventions requiring extensive experience and training to a limited cohort of providers. In Norway, this is a service provided by prehospital anaesthesiologist, usually from the Air Ambulance Services [2]. 
Pre-hospital anaesthesia with endotracheal intubation (ETI) is an advanced high-risk procedure, and failure can lead up to a "Cannot Intubate, Cannot Oxygenate (CICO)"-situation [3]. A CICO-situation in this setting requires a front-of-neck access, and a scalpel based, emergency cricothyroidotomy (EC) is the recommended procedure [4]. A prehospital observational study reported a surgical airway incidence of $1.2 \%$ among 7256 pre-hospital ETIs in a trauma population [5]. Thus, EC is a rare, but essential procedure, as it constitutes the last measure in difficult airway-algorithms $[2,4]$.

Prospective studies of EC in the prehospital environment may be impossible to perform. Simulation, however, offers the possibility to train and test skills for rare interventions, and provide clinical managers specific knowledge on advanced airway management quality, and crew performance [6]. In addition to technical skills, human factors and teamwork are major contributors to performance in high-risk work areas, such as prehospital EMS [7].

\section{Methods}

\section{Aim}

The aim of this study was to describe Air Ambulance-crews' performance in a simulated difficult airway scenario, assessing technical performance of pre-hospital anaesthesia with ETI and EC, and nontechnical aspects of management including communication, planning and team utilisation.

\section{Study design}

The study was an observational trial of team performance in a simulation scenario, assessed by video, using predefined scoring of technical and non-technical skills and time intervals. The study is reported according to the STROBE-statement recommendations, including extensions for simulation-based research [8].

\section{Setting}

Advanced prehospital airway-management in Norway is reserved for anaesthesiologist working in the EMS [2]. The main stem of this service consists of 13 Rotor Wing Air Ambulances (RW), seven Search and Rescue Helicopters (SAR) and five Rapid Response Car (RRC)-bases. The teams in the Rotor Wing Air Ambulances include additional staff with a Helicopter-EMS-crewmember (HCM) and a pilot [9]. RRCs include a Paramedic in addition to the anaesthesiologist. RRC with RW and SAR-teams are used when road access is faster and more convenient near air ambulance bases.

The study was conducted at a national Air Ambulance training facility, Camp Torpomoen. The camp is financed by The Norwegian Air Ambulance Foundation and invites personnel from all Air Ambulance Departments in Norway to lectures and simulated scenarios within medicine, rescue-operations, and flight operations. Participation is mandatory for HCMs and pilots in the civil Air Ambulance and anaesthesiologists from all services are invited to attend. One day prior to the trial all participants underwent theoretical and practical lectures on the learning objectives of the simulated scenario and 
advanced airway management, including front-of-neck EC with a bougie-assisted Rapid Four Step Technique (RFST) [10].

\section{Participants}

All anaesthesiologists, $\mathrm{HCMs}^{\prime}$ and pilots attending the training sessions were eligible for inclusion (Table 1).

Table 1

Professional characteristics of the 36 attending crews.

\begin{tabular}{|ll|}
\hline Crewmembers: & Professional characteristics: \\
\hline Anaesthesiologist & $\cdot$ Consultant, or more than four years' experience. \\
& $\cdot$ Prehospital training. \\
& - Working in Rotor Wing Air Ambulance, Rotor Wing Search or Rescue and Rapid \\
& Response Car. \\
& - Authorised as health personnel, nurse or paramedic. \\
& $\cdot$ Experienced from ambulance service. \\
& - Trained in rescue operations and as assistant to medical doctor on ground and \\
& to pilot in-flight. The roles are specific to the Norwegian Air Ambulance concept. \\
\hline Pilot & - Extensive experience from flight operations. \\
& - Minimal formal medical training. \\
\hline
\end{tabular}

\section{Test scenario}

Each crew was presented an identical scenario where they should do a primary response to assist Paramedics with a patient located in a parked ambulance. The clinical details are described in Table 2. 
Table 2

Description of the simulation scenario: Study Model, anamnestic details, facilitator instructions, equipment and learning objectives.

\section{Study Model \\ - Adult patient simulator ${ }^{\mathrm{a}}$ with advanced airway options. \\ - The manikin was built up with a large thorax and a thick neck, as in adipositas and goitre, and put in a "cannot intubate"-modus. \\ - After the first skin incision, the facilitator emptied a $10 \mathrm{cc}$ syringe with theatre-blood in the field. \\ - Vital signs and values (Blood pressure (BP), oxygen saturation $\left(\mathrm{SpO}_{2}\right)$, heart rate (HR), 3-lead electrocardiogram (ECG), End-tidal $\mathrm{CO}_{2}$ ) given remotely to the patient monitor when accomplished.}

Anamnestic -A paramedic-manned ambulance is requesting Air Ambulance for assistance.

details

- The patient is a sixty-year-old female, obese with an un-operated goitre and a history of breathing-problems and reduced general health for the last week. She is in respiratory distress, aggravated in the last hours.

Instruction for facilitators:

- Initial physiological status: GCS 13 points, $\mathrm{SpO}_{2}=85 \%, \mathrm{SBP} 105 \mathrm{mmHg}, \mathrm{HR}=110$ / $\min$.

- After appropriate first intervention (positioning and supplemental oxygen) transient improvement.

- Ultimately, patient deteriorates with falling $\mathrm{SpO}_{2}$, followed by decreasing GCS, forcing the crew to attempt an RSI. The manikin was put in a "cannot intubate"-modus, forcing the team to perform an EC.

Equipment Advanced Life Support-Ambulance.

Emergency bag equal to standard national Air Ambulance-level.[29]

Relevant emergency medications

Standard equipment for surgical airway:

- Scalpel No. 10 (Swann-Morton ${ }^{\circledR}$, England).

- Tracheal hook (18 cm retractor with blunt prong, Heljestrand®, Sweden).

- Cuffed $6.0 \mathrm{~mm}$ endotracheal tube cut at $20 \mathrm{~cm}$ (Mallinckrodt $\circledast$, Ireland).

- 10 cc syringe (Terumo $\AA$, Belgium).

- Self-inflatable bag (Ambu® Resuscitator)

- Frova Intubating Introducer ${ }^{\circledR}$ (Cook Medical, USA).

Video-laryngoscope was not available.

a. Lærdal SimMan 3G, Lærdal Foundation, Norway.

b. SimMon, Castle + Andersen Aps, Denmark. 


\begin{tabular}{|c|c|}
\hline \multirow{5}{*}{$\begin{array}{l}\text { Study } \\
\text { Model }\end{array}$} & - Adult patient simulator ${ }^{\mathrm{a}}$ with advanced airway options. \\
\hline & $\begin{array}{l}\text { - The manikin was built up with a large thorax and a thick neck, as in adipositas and } \\
\text { goitre, and put in a "cannot intubate"--modus. }\end{array}$ \\
\hline & $\begin{array}{l}\text { After the first skin incision, the facilitator emptied a } 10 \mathrm{cc} \text { syringe with theatre-blood } \\
\text { in the field. }\end{array}$ \\
\hline & - Vital signs and values (Blood pressure $(\mathrm{BP})$, oxygen saturation $\left(\mathrm{SpO}_{2}\right)$, heart rate \\
\hline & $\begin{array}{l}(\mathrm{HR}) \text {, 3-lead electrocardiogram (ECG), End-tidal } \mathrm{CO}_{2} \text { ) given remotely }{ }^{\mathrm{b}} \text { to the patient } \\
\text { monitor when accomplished. }\end{array}$ \\
\hline \multirow{3}{*}{$\begin{array}{l}\text { Learning } \\
\text { objectives }\end{array}$} & - Identify a difficult airway \\
\hline & $\begin{array}{l}\text { - Ensure adequate monitoring, preparations and conduction of Rapid Sequence } \\
\text { Induction. }\end{array}$ \\
\hline & - Solve CICO with an EC \\
\hline \multicolumn{2}{|c|}{ a. Lærdal SimMan 3G, Lærdal Foundation, Norway. } \\
\hline \multicolumn{2}{|c|}{ b. SimMon, Castle + Andersen Aps, Denmark. } \\
\hline
\end{tabular}

The participants were encouraged to manage the patient during simulation as in a real mission.

The scenario was led by senior facilitators with extensive experience from Air Ambulance clinical service and simulation teaching. The facilitators ran the simulation based on a written manual with predetermined responses to treatment options and the study objectives. Manikin and monitors were operated remotely by an assistant (Table 2).

The scenario progressed in a stepwise manner, in order to let all participants face the learning objectives (Table 2).

\section{Data Collection and Study Variables}

The scenario was filmed with a camera placed in the back of the ambulance providing a clear view to the scenario. Our data material consists of video-material of the crews' communications and actions during the simulation. To reduce bias and to quantify performance in an advanced clinical scenario, predefined time intervals, binary quality indicators of procedural steps, and quality indicators of non-technical skills were extrapolated from the video-material. These were based on current literature and the Standard Operating Procedure, Oslo University Hospital, Air Ambulance Department [2, 4, 11-13].

Success was defined as being able to do an EC and perform an ETI through membrana cricothyroidea and start ventilation with a self-inflatable bag (Fig. 1).

Time intervals were measured from (1) decision to do a surgical airway, and (2) the first skin incision with the scalpel. Stop-point was the first successful ventilation with a self-inflatable bag on the tube successfully placed in the trachea on the manikin. 
The Anaesthetists non-technical skills (ANTS) -system is a validated approach to evaluate the nontechnical aspects of crew performance $[13,14]$. We developed a structured list of performance observations which could be scored with three possible variables (Yes/No/Partially). These points covered the four ANTS-categories: Situation awareness, team working, task management and decision making.

\section{Statistical methods}

Performance indicators are presented as numbers and percentages. Time intervals are stated in seconds with mean values, standard deviation and range.

\section{Results}

All 36 eligible Air Ambulance crews attending the camp participated in the study. The crews represented all Air Ambulance bases in Norway, including three doctors from the Air Force SAR-Helicopter and four doctors from the RRC, Oslo University Hospital (Table 1).

All crews successfully conducted the EC achieving ventilation with the bougie-assisted RFST-technique. The mean time interval for the procedure from first incision to ventilation was 118 seconds (SD: \pm 70 , range: 40-322), and the duration from doctor's decision to perform an EC to successful ventilation was 153 seconds (SD: $\pm 80 \mathrm{sec}$, range: 69-369).

Completed procedural steps by the crews with respect to monitoring, equipment and management are given in Table 3. Almost all crews established basic monitoring with pulse oximetry and non-invasive blood pressure, while less than one in four crews established three-lead electrocardiogram monitoring. Five crews prioritized invasive blood pressure monitoring. Two-thirds ensured that equipment for suction was present, while only $56 \%$ tested that the equipment was working. Almost all crews established a running intravenous line with crystalloids, but very few gave a fluid bolus prior to first Rapid Sequence Induction (RSI) attempt. Similarly, only four crews administered vasoactive medication prior to the RSI procedure. Less than half of the crews positioned the neck in "sniffing position" before RSI, while 50\% palpated the cricothyroid membrane prior to induction. Prior to the EC procedure, the majority failed to elevate and extend the neck for optimised access to the cricothyroid membrane. Post-intubation, all crews assessed tube placement by auscultation, while half of the crews promptly used capnography for verifying tube placement. 
Table 3

Procedural steps performed by crews stated in absolute numbers and percentages.

\begin{tabular}{|c|c|c|c|c|}
\hline & STEPS: & $\begin{array}{l}\text { Performed } \\
\mathrm{n}(\%)\end{array}$ & $\begin{array}{l}\text { Not } \\
\text { performed } \\
n(\%)\end{array}$ & COMMENT / DESCRIPTION \\
\hline \multirow{2}{*}{$\begin{array}{l}E \\
Q \\
U\end{array}$} & Pulse oximetry & $34(94)$ & $2(6)$ & $\begin{array}{l}\text { Monitoring with pulse oximetry initiated } \\
\text { before RSI }\end{array}$ \\
\hline & Three-lead ECG & $8(22)$ & $28(78)$ & $\begin{array}{l}\text { Monitoring with three-lead ECG initiated } \\
\text { before RSI }\end{array}$ \\
\hline \multirow{2}{*}{$\begin{array}{l}\mathrm{I} \\
\mathrm{P} \\
\mathrm{M}\end{array}$} & $\begin{array}{l}\text { Non-invasive blood } \\
\text { pressure (NIBP) }\end{array}$ & $35(97)$ & $1(3)$ & Monitoring with NIBP initiated before RSI \\
\hline & $\begin{array}{l}\text { Invasive blood } \\
\text { pressure (IBP) }\end{array}$ & $5(14)$ & $31(86)$ & Monitoring with IBP initiated before RSI \\
\hline \multirow{5}{*}{$\begin{array}{l}E \\
N \\
T\end{array}$} & Intravenous fluid & $35(97)$ & $1(3)$ & $\begin{array}{l}\text { Establishing intravenous infusion with } \\
\text { crystalloid }\end{array}$ \\
\hline & $\begin{array}{l}\text { Additional } \\
\text { intravenous route }\end{array}$ & $13(36)$ & $23(64)$ & $\begin{array}{l}\text { Placement of extra peripheral venous } \\
\text { cannula }\end{array}$ \\
\hline & Oxygen present & $32(89)$ & $4(11)$ & $\begin{array}{l}\text { Presence of oxygen tank addresses loudly by } \\
\text { one crewmember }\end{array}$ \\
\hline & $\begin{array}{l}\text { Suction present } \\
\text { and tested }\end{array}$ & $20(56)$ & $16(44)$ & $\begin{array}{l}\text { Presence of suction addressed loudly by one } \\
\text { crewmember, and functional testing applied }\end{array}$ \\
\hline & $\begin{array}{l}\text { Preparation of } \\
\text { equipment }\end{array}$ & $15(41)$ & $21(59)$ & $\begin{array}{l}\text { Complete planning and preparing for } \\
\text { additional airway equipment before RSI }\end{array}$ \\
\hline \multirow{3}{*}{$\begin{array}{l}P \\
R \\
0\end{array}$} & $\begin{array}{l}\text { Optimisation of } \\
\text { posture }\end{array}$ & $24(67)$ & $12(33)$ & $\begin{array}{l}\text { Raising back of ambulance-stretcher when } \\
\text { arriving to patient }\end{array}$ \\
\hline & Preoxygenation & $35(97)$ & $1(3)$ & Preoxygenation before conduction of RSI \\
\hline & $\begin{array}{l}\text { Early assisted } \\
\text { ventilation }\end{array}$ & $16(44)$ & $20(56)$ & $\begin{array}{l}\text { Bag-valve-mask ventilation initiated first two } \\
\text { minutes }\end{array}$ \\
\hline \multirow{2}{*}{$\begin{array}{l}E \\
S \\
S\end{array}$} & Fluid bolus & $3(8)$ & $33(92)$ & $\begin{array}{l}\text { Deliberately increasing intravascular volume } \\
\text { before RSI }\end{array}$ \\
\hline & Vasoactive bolus & $4(11)$ & $32(89)$ & $\begin{array}{l}\text { Deliberately increasing vascular resistance } \\
\text { before RSI }\end{array}$ \\
\hline $\begin{array}{l}\mathrm{R} \\
\mathrm{E}\end{array}$ & $\begin{array}{l}\text { Patient elevated } \\
\text { head }\end{array}$ & $14(39)$ & $22(61)$ & $\begin{array}{l}\text { Establishing the patient in "sniffing position" } \\
\text { with an elevated thorax, suitable for RSI of } \\
\text { adipose patient. }\end{array}$ \\
\hline $\begin{array}{l}L \\
A\end{array}$ & $\begin{array}{l}\text { Doctor placed } \\
\text { lateral to patient for } \\
\text { RFST }\end{array}$ & $34(94)$ & $2(6)$ & $\begin{array}{l}\text { Taking position at side of patients' neck, } \\
\text { opposed to standing behind head before } \\
\text { RFST }\end{array}$ \\
\hline
\end{tabular}




\begin{tabular}{|lllll|}
\hline E & STEPS: & $\begin{array}{l}\text { Performed } \\
\mathbf{n}(\%)\end{array}$ & $\begin{array}{l}\text { Not } \\
\text { performed } \\
\mathbf{n}(\%)\end{array}$ & COMMENT / DESCRIPTION \\
\hline $\begin{array}{l}\text { Active extension of } \\
\text { neck }\end{array}$ & $15(42)$ & $21(58)$ & $\begin{array}{l}\text { Adequate optimization of patient before } \\
\text { RFST }\end{array}$ \\
\hline $\begin{array}{l}\text { Active build-up } \\
\text { under shoulders }\end{array}$ & $6(17)$ & $30(83)$ & $\begin{array}{l}\text { Adequate optimization of patient before } \\
\text { RFST }\end{array}$ \\
\hline $\begin{array}{l}\text { Doctor preparing } \\
\text { medication }\end{array}$ & $2(6)$ & $34(94)$ & $\begin{array}{l}\text { When not performed, HCM or pilot is } \\
\text { preparing the RSI medications. }\end{array}$ \\
\hline $\begin{array}{l}\text { Early capnography } \\
\text { Auscultation }\end{array}$ & $19(53)$ & $17(47)$ & $\begin{array}{l}\text { Connecting capnography first 10 seconds } \\
\text { after ETT-placement }\end{array}$ \\
\hline
\end{tabular}

The evaluation of non-technical skills is provided in Table 4. The crews displayed high situational awareness in terms of collecting adequate anamnestic information and recognition of a difficult airway situation. Closed-loop communication was widely employed, and available resources utilised with the majority of crewmembers partaking in the medical management; the HCM was participating in clinical decision-making and treatment in all cases. The pilots were actively involved in the scenario, e.g. with equipment assistance, in 28 (78\%) of the simulations. Further, in one third of the cases, the pilots' contribution played a major role in problem-solving, e.g.: the pilot being the first crewmember to address difficult airway, preparing difficult airway equipment, or taking initiative to improve positioning of the patient to facilitate the airway procedure. 
Table 4

Non-technical skills demonstrated by crews during simulation

\begin{tabular}{|c|c|c|c|c|c|}
\hline & $\begin{array}{l}\text { Non-technical } \\
\text { skills }\end{array}$ & $\begin{array}{l}\text { Performed } \\
\text { n (\%) }\end{array}$ & $\begin{array}{l}\text { Not } \\
\text { performed } \\
n(\%)\end{array}$ & $\begin{array}{l}\text { Partially } \\
\text { performed } \\
\mathrm{n}(\%)\end{array}$ & $\begin{array}{l}\text { COMMENT / } \\
\text { DESCRIPTION }\end{array}$ \\
\hline \multirow[t]{2}{*}{$\begin{array}{l}\text { Situation } \\
\text { awareness }\end{array}$} & Anamnesis & $34(94)$ & $1(3)$ & $1(3)$ & $\begin{array}{l}\text { Obtaining adequate } \\
\text { anamnestic details } \\
\text { from paramedic on- } \\
\text { scene }\end{array}$ \\
\hline & $\begin{array}{l}\text { Recognition of } \\
\text { difficult airway }\end{array}$ & $34(94)$ & $2(6)$ & $\begin{array}{l}\text { Not } \\
\text { applicable }\end{array}$ & $\begin{array}{l}\text { Possible difficult airway } \\
\text { addressed loudly by one } \\
\text { crewmember }\end{array}$ \\
\hline \multirow[t]{3}{*}{$\begin{array}{l}\text { Team } \\
\text { working }\end{array}$} & $\begin{array}{l}\text { HCM } \\
\text { involvement }\end{array}$ & $36(100)$ & 0 & 0 & $\begin{array}{l}\text { HCM actively } \\
\text { participating in } \\
\text { assessment, treatment } \\
\text { and use of equipment }\end{array}$ \\
\hline & $\begin{array}{l}\text { Pilot } \\
\text { involvement }\end{array}$ & $28(78)$ & $8(22)$ & 0 & $\begin{array}{l}\text { Pilot participating in } \\
\text { assessment, } \\
\text { preparation or } \\
\text { treatment. }\end{array}$ \\
\hline & $\begin{array}{l}\text { Pilot major } \\
\text { contribution }\end{array}$ & $11(33)$ & $22(66)$ & $\begin{array}{l}\text { Not } \\
\text { applicable }\end{array}$ & $\begin{array}{l}\text { Pilot actively and } \\
\text { independently } \\
\text { contributing to } \\
\text { assessment, } \\
\text { preparation or } \\
\text { treatment. }\end{array}$ \\
\hline \multirow[t]{3}{*}{$\begin{array}{l}\text { Task } \\
\text { management }\end{array}$} & $\begin{array}{l}\text { Brief RSI } \\
\text { medications }\end{array}$ & $33(92)$ & $2(6)$ & $1(3)$ & $\begin{array}{l}\text { Giving a concise brief } \\
\text { on which medications } \\
\text { and dosage before RSI }\end{array}$ \\
\hline & $\begin{array}{l}\text { Brief Plan B for } \\
\text { alternative } \\
\text { airway }\end{array}$ & $25(69)$ & $8(22)$ & $3(9)$ & $\begin{array}{l}\text { Supraglottic airway } \\
\text { device if RSI-failure. }\end{array}$ \\
\hline & $\begin{array}{l}\text { Brief Plan C for } \\
\text { alternative } \\
\text { airway }\end{array}$ & $11(30)$ & $14(39)$ & $11(31)$ & $\begin{array}{l}\text { Surgical front of neck- } \\
\text { access if RSI-failure }\end{array}$ \\
\hline \multirow[t]{2}{*}{$\begin{array}{l}\text { Decision } \\
\text { making }\end{array}$} & $\begin{array}{l}\text { Closed-loop } \\
\text { communication }\end{array}$ & $33(92)$ & $3(8)$ & 0 & $\begin{array}{l}\text { Deliberated use of } \\
\text { closed loop in team } \\
\text { communication }\end{array}$ \\
\hline & Checklist & $1(3)$ & $35(97)$ & 0 & $\begin{array}{l}\text { Use of standardized } \\
\text { checklist before RSI }\end{array}$ \\
\hline
\end{tabular}

The crew resource utilisation was also evident by the fact that in 34 of 36 crews, other crewmembers than the doctor were preparing the medication (Table 3). A full "double-signature" check of medications was subsequently performed. 
At induction of anaesthesia, the majority did an RSI-brief, and included an alternative airway strategy with the use of a supraglottic airway device. Only one third of these briefs included a plan for EC.

Only one crew used a structured checklist during the scenario.

\section{Discussion}

Our study shows that in a high-fidelity simulation with a manikin model, Norwegian Air Ambulance crews managed to solve a difficult airway situation successful and in a timely manner. Some heterogeneity is observed in the technical conduct of the scenarios, but effective team cooperation and task management characterise the crews' performance.

The high success rate is in accordance with clinical data from a previous large observational study [5]. Procedural duration for RFST was 118 seconds, with maximum time 322 seconds.

Experimental studies have found time expenditure for RFST-procedure in a range about 60 seconds [1517]. These studies have in common that they have been performed on various laryngeal models, in which the operator does not have to consider other clinical factors. Often the procedures have been performed by a single provider without assistance, to allow for comparison of different techniques. Such experimental settings may not be completely generalisable to the clinical setting as the stress of a CICOsituation may not have been reproduced.

In this setting another important time interval is from decision to do EC, until completion. A mean duration of 159 seconds is in our opinion both realistic and an acceptable result, indicating that most crews were prepared to convert from an endotracheal intubation procedure to an EC procedure.

A standardised RSI-protocol is advised in emergency medicine [18]. Protocol briefing with alternative airway management plans before problems arise ensures that the entire crew is prepared and knows their role in a critical situation like $\mathrm{CICO}$ [19]. Air Ambulance crews who fulfil these requirements can start the EC more immediately when the attempted endotracheal intubation must be aborted. Failure to optimize patient position, lack of thorough brief of alternative airway plans and differences in preparation of equipment can be contributing factors to long procedural duration in some crews.

Prehospital advanced airway management is a complex medical procedure. The majority of the learning objectives are fulfilled by all crews. Recognition of a potential difficult airway was stated early, yet only half of the doctors palpated the neck anatomy before induction of anaesthesia. We found that RSIpreparation was acceptable, and the majority followed the predetermined objectives. Important medical treatment was provided with little delay. Our findings indicate that there are room for improvement regarding preparations. Correct positioning of the patient before RSI and re-positioning to achieve elevation of the neck before $\mathrm{EC}$, improves success rates. Extension of the neck is recommended before the EC procedure to ease passing of the endotracheal tube (ETT) [20]. Even if the RFST was carried out 
correctly, some crews experienced difficulties when they were ready to pass the ETT through the membrane.

ETI must be confirmed with end-tidal $\mathrm{CO}_{2}$, and this is well known to Air Ambulance-providers [4]. Our study shows that this can be forgotten in a stressful setting. The use of checklists was almost nonexisting. A recent meta-analysis indicates that there is no association between checklists and better clinical outcome [21]. On the other hand, implementation of checklists has been advocated in the literature, and it can be argued that stricter adherence to standard operating procedures can optimise the advanced prehospital airway management [22].

Identifying treatment options and selecting airway management was also indicating that the Air Ambulance crews have a good situational awareness. The Crew Resource Management (CRM)-concept is derived from aviation and is designed to reduce human errors by using safety-management principles and training interventions [23]. The field of anaesthesiology was the first to adapt these principles in medicine. Our study indicate that CRM is well incorporated in Norwegian H-EMS; e.g., there was extensive use of closed-loop communication and duplication checking. The HCM was supportive and assisted the doctor to a great extent in all simulations. We also found that the pilot was contributing exceedingly, and that their contribution was crucial in almost one third of the cases. Despite no formal education in emergency medicine, the pilots' clinical understanding of the situation was higher than what may be expected. We observed that when the workload was high for the physician and $\mathrm{HCM}$, the pilots took the role of the qualified assistant, and was able to provide important inputs to his colleagues. This implies high utilization of the available resources. A previous study of Norwegian H-EMS reported need for improvement in simulation training and non-technical skills [24]. Our findings correspond better with several more recent studies that imply a shift towards increased focus on these important aspects of emergency medical care $[25,26]$.

\section{Limitations:}

This is an experimental setting with obvious lack of realism and feeling of lives at stake, and performance may be different in real life. Medical simulation is to a certain degree a realistic proxy for real emergency situations, and its use is supported in literature [27]. It has been claimed that when experienced anaesthesiologists struggle with medical emergencies in simulation it also indicates suboptimal real life patient care [28].

All participants attended a lecture and practical training the day before the scenario. It is likely that longer interval between training and testing, would result in poorer performance.

A clinical scenario with different participants and facilitators will have different group dynamics and there will be variation in performance, both regarding preparations and treatment. Thus, a limitation of this study is the human aspect in the difference in facilitators' feedback and case progression during simulation. The clinical course of the case was directed by the manual, but at the facilitators' discretion. Despite efforts to standardise the interventions, advanced medical simulation with different crews is 
complex and it is not possible to reproduce identical clinical trajectories. However, deviations from optimal management in the scenarios are generally time consuming. Long procedural time is therefore, in our opinion, the most objective indication for suboptimal treatment in this simulated setting.

\section{Conclusion}

The study shows that Norwegian Air Ambulance crews manage to solve a prehospital CICO-situation with an EC under stressful conditions within a reasonable timeframe. We observed a high level of performance regarding both technical- and non-technical skills among the crews. Effective communication and teamwork, utilizing all crew resources, characterise the scenarios. Comparison with our predetermined objectives also disclosed some discrepancies with a substantial proportion of the crews not addressing key steps of monitoring and preparation. The use of a structured checklist was almost non-existing. How this relates the observed discrepancies is yet to be determined. We recommend future studies that assess the use of checklists and how they affect both time expenditure and compliance to standard operating procedures in similar scenarios.

\section{Abbreviations}

EMS - Emergency Medical Services

ETI - Endotracheal Intubation

CICO - Cannot Intubate, Cannot Oxygenate

RW - Rotor Wing

SAR - Search And Rescue

RRC - Rapid Response Car

HCM - Helicopter-EMS-crewmember

RFST - Rapid Four Step Technique

ANTS - The Anaesthetists Non-Technical Skills

RSI - Rapid Sequence Induction

ETT - Endotracheal Tube

CRM - Crew Resource Management

\section{Declarations}




\section{Ethics approval and consent to participate:}

The Regional Committee for Medical Research South East Norway exempted this study from formal ethical approval (2017/866); and data handling was in accordance with the local Data Protection Officer at Vestre Viken Health Trust (16/00117-65).

All participants signed an informed consent form.

All methods were performed in accordance with the relevant guidelines and regulations.

\section{Consent for publication:}

Not applicable.

\section{Availability of data and material:}

The dataset extracted from the video material regarding the pre-defined observational points is provided in a separate file. The video material is not published due to privacy considerations for the participants. The video material is stored on the research server at Vestre Viken Hospital Trust, and insight can be considered by the authors on reasonable request.

\section{Competing interests:}

The authors declare that they have no competing interests.

\section{Funding:}

ÅEA was partially salaried as a PhD-candidate from The Norwegian Air Ambulance Foundation.

\section{Authors' contributions:}

ÅEA conducted the data collection. All authors contributed to planning the study, data-analysis and writing the paper.

\section{Acknowledgements:}

We are grateful to the participants at Camp Torpomoen and the arranging committee at The Norwegian Air Ambulance Foundations for contributing to this study.

\section{References}

1. Piegeler T, Neth P, Schlaepfer M, Sulser S, Albrecht R, Seifert B, Spahn DR, Ruetzler K: Advanced airway management in an anaesthesiologist-staffed Helicopter Emergency Medical Service (HEMS): A retrospective analysis of 1047 out-of-hospital intubations. Resuscitation 2016, 105:66-69. 
2. Rehn M, Hyldmo PK, Magnusson V, Kurola J, Kongstad P, Rognas L, Juvet LK, Sandberg M:

Scandinavian SSAI clinical practice guideline on pre-hospital airway management. Acta Anaesthesiol Scand 2016, 60(7):852-864.

3. Diggs LA, Yusuf JE, De Leo G: An update on out-of-hospital airway management practices in the United States. Resuscitation 2014, 85(7):885-892.

4. Frerk C, Mitchell VS, McNarry AF, Mendonca C, Bhagrath R, Patel A, O'Sullivan EP, Woodall NM, Ahmad I, Difficult Airway Society intubation guidelines working g: Difficult Airway Society 2015 guidelines for management of unanticipated difficult intubation in adults. $\mathrm{Br} \mathrm{J}$ Anaesth 2015, 115(6):827-848.

5. Lockey D, Crewdson K, Weaver A, Davies G: Observational study of the success rates of intubation and failed intubation airway rescue techniques in 7256 attempted intubations of trauma patients by pre-hospital physicians. Br J Anaesth 2014, 113(2):220-225.

6. Sollid SJ, Heltne JK, Soreide E, Lossius HM: Pre-hospital advanced airway management by anaesthesiologists: is there still room for improvement? Scand J Trauma Resusc Emerg Med 2008, 16:2.

7. Manser T: Teamwork and patient safety in dynamic domains of healthcare: a review of the literature. Acta Anaesthesiol Scand 2009, 53(2):143-151.

8. Cheng A, Kessler D, Mackinnon R, Chang TP, Nadkarni VM, Hunt EA, Duval-Arnould J, Lin Y, Cook DA, Pusic $M$ et al: Reporting guidelines for health care simulation research: extensions to the CONSORT and STROBE statements. Adv Simul (Lond) 2016, 1:25.

9. http://www.luftambulanse.no/about-national-air-ambulance-services-norway. Accessed January, 2022.

10. Morris A, Lockey D, Coats T: Fat necks: modification of a standard surgical airway protocol in the prehospital environmental. Resuscitation 1997, 35(3):253-254.

11. Burgess MR, Crewdson K, Lockey DJ, Perkins ZB: Prehospital emergency anaesthesia: an updated survey of UK practice with emphasis on the role of standardisation and checklists. Emerg Med $\mathrm{J}$ 2018, 35(9):532-537.

12. Lockey DJ, Crewdson K, Davies G, Jenkins B, Klein J, Laird C, Mahoney PF, Nolan J, Pountney A, Shinde S et al: AAGBI: Safer pre-hospital anaesthesia 2017: Association of Anaesthetists of Great Britain and Ireland. Anaesthesia 2017, 72(3):379-390.

13. Fletcher G, Flin R, McGeorge P, Glavin R, Maran N, Patey R: Anaesthetists' Non-Technical Skills (ANTS): evaluation of a behavioural marker system. Br J Anaesth 2003, 90(5):580-588.

14. Burke CS, Salas E, Wilson-Donnelly K, Priest $\mathrm{H}$ : How to turn a team of experts into an expert medical team: guidance from the aviation and military communities. Qual Saf Health Care 2004, 13 Suppl 1:i96-104.

15. Dimitriadis JC, Paoloni R: Emergency cricothyroidotomy: a randomised crossover study of four methods. Anaesthesia 2008, 63(11):1204-1208. 
16. Chrisman L, King W, Wimble K, Cartwright S, Mohammed KB, Patel B: Surgicric 2: A comparative bench study with two established emergency cricothyroidotomy techniques in a porcine model. $\mathrm{Br} J$ Anaesth 2016, 117(2):236-242.

17. Andresen AEL, Kramer-Johansen J, Kristiansen T: Percutaneous vs surgical emergency cricothyroidotomy: An experimental randomized crossover study on an animal-larynx model. Acta Anaesthesiol Scand 2019, 63(10):1306-1312.

18. Lyon RM, Perkins ZB, Chatterjee D, Lockey DJ, Russell MQ, Kent S, Sussex Air Ambulance T:

Significant modification of traditional rapid sequence induction improves safety and effectiveness of pre-hospital trauma anaesthesia. Crit Care 2015, 19:134.

19. Woodall N, Frerk C, Cook TM: Can we make airway management (even) safer?-lessons from national audit. Anaesthesia 2011, 66 Suppl 2:27-33.

20. Hamaekers $A E$, Henderson JJ: Equipment and strategies for emergency tracheal access in the adult patient. Anaesthesia 2011, 66 Suppl 2:65-80.

21. Turner JS, Bucca AW, Propst SL, Ellender TJ, Sarmiento EJ, Menard LM, Hunter BR: Association of Checklist Use in Endotracheal Intubation With Clinically Important Outcomes: A Systematic Review and Meta-analysis. JAMA Netw Open 2020, 3(7):e209278.

22. Crewdson K, Lockey D, Voelckel W, Temesvari P, Lossius HM, Group EMW: Best practice advice on pre-hospital emergency anaesthesia \& advanced airway management. Scand J Trauma Resusc Emerg Med 2019, 27(1):6.

23. O'Dea A, O'Connor P, Keogh I: A meta-analysis of the effectiveness of crew resource management training in acute care domains. Postgrad Med J 2014, 90(1070):699-708.

24. Abrahamsen HB, Sollid SJ, Ohlund LS, Roislien J, Bondevik GT: Simulation-based training and assessment of non-technical skills in the Norwegian Helicopter Emergency Medical Services: a crosssectional survey. Emerg Med J 2015, 32(8):647-653.

25. Bredmose PP, Hagemo J, Roislien J, Ostergaard D, Sollid S: In situ simulation training in helicopter emergency medical services: feasible for on-call crews? Adv Simul (Lond) 2020, 5:7.

26. Langdalen H, Abrahamsen EB, Sollid SJM, Sorskar LIK, Abrahamsen HB: A comparative study on the frequency of simulation-based training and assessment of non-technical skills in the Norwegian ground ambulance services and helicopter emergency medical services. BMC Health Serv Res 2018, 18(1):509.

27. Komasawa N, Berg BW: Simulation-based Airway Management Training for Anesthesiologists - A Brief Review of its Essential Role in Skills Training for Clinical Competency. The journal of education in perioperative medicine: JEPM 2017, 19(4):E612.

28. Weinger MB, Banerjee A, Burden AR, Mclvor WR, Boulet J, Cooper JB, Steadman R, Shotwell MS, Slagle JM, DeMaria S, Jr. et al: Simulation-based Assessment of the Management of Critical Events by Board-certified Anesthesiologists. Anesthesiology 2017, 127(3):475-489.

29. Schmid M, Schuttler J, Ey K, Reichenbach M, Trimmel H, Mang H: Equipment for pre-hospital airway management on Helicopter Emergency Medical System helicopters in central Europe. Acta 
Anaesthesiol Scand 2011, 55(5):583-587.

\section{Figures}

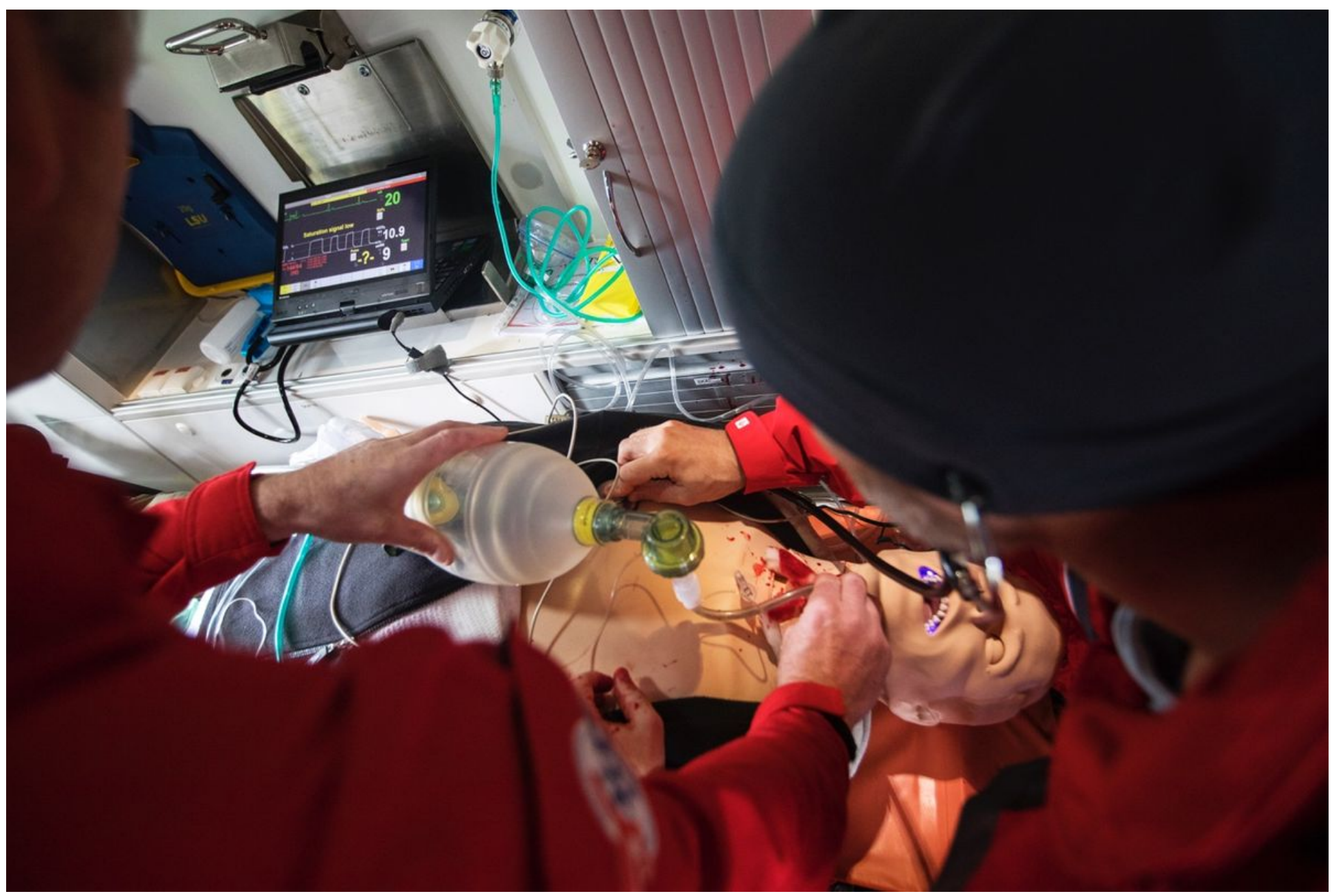

\section{Figure 1}

Doctor and HCM from the Air Ambulance working on the study model.

\section{Supplementary Files}

This is a list of supplementary files associated with this preprint. Click to download.

- BMCAndresenDataset.xIsx

- AndresenStrobe.pdf 